\title{
Relationship of Strategy Execution Plan Dimensions on Organization Performance of Higher Educational Institution in Palestine
}

\author{
Mohammed Siam ${ }^{1} \&$ Haim Hilman ${ }^{1}$ \\ ${ }^{1}$ College of Business, University Utara Malaysia, Malaysia \\ Correspondence: Mohammed Siam, College of Business, University Utara Malaysia, Malaysia. E-mail: \\ mohpalestine@gmail.com
}

Received: April 8, 2014 Accepted: May 4, 2014 Online Published: June 25, 2014

doi:10.5539/ass.v10n13p131 URL: http://dx.doi.org/10.5539/ass.v10n13p131

\begin{abstract}
Today undoubtedly, the environment has become increasingly uncertain toward higher learning institutions. Therefore, successful execution of strategies in the midst of this uncertainty has become very crucial for the organizations because the success or failure of learning institutions depends to a greater extent on their ability to understand both the internal and external forces in the learning domain. However, this paper investigates the relationship between strategy execution plan dimensions and organizational performance in the higher educational institutions in Palestine. The study generated a quantitative questionnaire data from 255 respondents representing the top, medium and low management level of the higher educational institutions in Palestine. Data was analyzed using the partial least squares-structural equation model PLS-SEM. Overall, the finding revealed that strategy execution plan dimensions are significantly related to organizational performance as hypothesized. Discussions on the findings, implication and limitation are also provided.
\end{abstract}

Keywords: execution objectives, execution tasks, higher learning institutions, organizational performance, Palestine

\section{Introduction}

The introduction of strategic management, such as the process of strategic planning combined with strategy execution and control, has opened up a formal framework for dealing with this problem; however, it has failed to attract much academic attention (Gottschalk, 2008). Noble (1999) for example, argues that we are still witnessing a noticeable absence of a deep and coherent body of literature in the field of strategy implementation which is believed to have consequences on business practice. Hrebiniak (2006) argues that it is always easier for managers to develop a strategy than execute such a plan. To overcome these huge problems of strategy implementation, an author such as Connor (2001) has called for studies in this area to strongly emphasize the practical problems of strategy implementation. For Noble (1999), the strategy execution as a stage involves joining strategic alternatives into a plan to use and process that turns marketing plans into action assignments and ensure that such assignments are implemented in a manner that fulfils the plans as stated earlier. According to Crittenden and Crittenden (2008), effective factors for strategy execution include effective elements to execute strategic plan, enhance clearance and measurable goals, integrate plans/activities across different initiatives and finally enlarges sustainability of the plan. However, failure to do so may lead organizations to failure.

Furthermore, the execution tasks are defined which are needed to achieve the objectives of the implementation with the execution responsibilities which assign clear responsibilities for the execution plan (Maas, 2008). Similarly, Hrebiniak $(2005,2006)$ and Gurkov (2009) argue that even well-prepared and sound plans die if the implementers fail to confront difficult organizational and political obstacles that stand in the way of effective execution. Therefore, strategy executors must persuade all relevant employees to carry out all the activities that are necessary to implement the strategy (Hrebiniak 2005). Al-Ghamdi (1998) for example, reports that $75 \%$ of companies lack the effective co-ordination of execution activities. According to Kaplan and Norton (2006), this problem can be partly solved by using strategy maps which connect a strategy paper with an operative execution plan and can therefore substitute organizing efforts for strategy execution. Alamsjah (2011) found that the execution plan is the fourth factor that hinders the success of strategy execution, and he argues that, with regard to the clear strategy, it is easier for the managers to prepare execution plans that consist of prioritizing work programs and budgets. 
The Palestinian context lacks studies, represented mainly by the poor level of general knowledge in the field of strategy execution. In other words, serious empirical research about the factors of strategy execution with particular interest in the Palestinian higher educational institutions has been neglected. In spite of the considerable number of research on strategy, little attention has been given to the execution plan. Obviously, studies focusing on execution plan and organizational performance seem to be limited. (Mieso, 2010; Rahimian, Polychronakis \& Sharp, 2009; Malik, 2007; Delisi, 2006; Alashloo, Castka \& Sharp, 2005; Hrebiniak, 2005; Kaplan \& Norton, 2005; Charan \& Colvin, 2002; Johnson, 2002; Al-Gamdi, 2006, 1998; Alexander, 1991, 1985). Further, these previous studies view that the execution plan is the major obstacle to the success and performance of the organization. Based on what has been mentioned, this paper investigates the influence of strategy execution plan dimensions of the organizational performance in the higher educational institutions in Palestine.

\section{Literature Review}

\subsection{Execution Plan}

In an attempt to describe the execution plan, Hrebiniak and Joyce (1984) defined the implementation plan as a 'comprehensive plan that clearly outlines the objectives of an implementation as the activities which are needed to achieve these objectives and who are responsible for these activities'. They noted that an implementation plan is concrete in nature. The codification of an execution plan with its strategy and execution is believed to have a positive influence on both the execution success and the organizational performance (Hussy, 1996). Maas (2008) in his study of implementation plan also highlighted that the execution plan and its dimension mentioned by the interviewees is the fourth key success factor of 32 factors investigated in the field and a significant factor related to the organizational performance. However, despite its perceived importance, many organizations still lack good workable execution plans. Accordingly, it is noted that an execution plan should outline in detail the way and manner a strategic vision is to be attained. The implementation plan should translate the strategy into day-to-day management of the organization. Moreover, it could equally be an aspect of the strategic plan. On the other hand, it could also consist of the objectives of the implementation, the tasks and activities that are required to implement the strategy and the responsibilities for the achievement of those tasks as highlighted by Cater ad Puko (2010) and Maas (2008). Similarly, Hrebiniak and Joyce (1984) argued that there is limited evidence found on the subject of having a concrete implementation plan in the strategy execution plan literature. In line with this, Kaplan (1995) posits that a strategic plan cannot be executed when it is not translated into operational terms. He argued that the strategy should be distilled into a single, coherent document (Allio, 2005). However, Maas (2008) found that having a concrete, detailed and comprehensive execution plan can have a positive influence on the level of success of an implementation effort and can be a critical factor to raise organizational performance. The author further noted that the managers have the tendency to keep the strategy rather be vague and ambiguous. Consequently, policies and strategies often lack a concrete and detailed execution plan. Mintzberg (1990) argued that (concrete) plans are by their nature designed to promote inflexibility. Hence, when the situation changes, the plan can become (partly) obsolete (Mintzberg, 1990). In the policy implementation literature, Brinkerhoff (1996) also argued that what is critical to (policy) execution management is the ability to learn while doing and maintain flexibility. Therefore, it can be beneficial to have a less concrete execution plan (Maas, 2008). In line with the above description, this paper assumed that there is a correlation between execution plan and organisational performance.

\subsubsection{Execution Objectives}

By a simple definition, an objective means a statement showing what the organization tends to achieve. Johnson and Scholes (2002) and Lynch (2003) described an objective as a precise statement of what is to be achieved and when the results are to be accomplished, which is often quantified. Thus, there is a need to translate the strategy into a clear, concrete, measurable, and feasible execution for the purpose of achieving the organizational execution performance as well as the performance of the organization. First and foremost, it is imperative that organizational members, who are involved in the execution effort, need to know what its general objectives are and what needs to be achieved in order to implement the strategy successfully. Besides, organizational members need to know what concrete objectives they have to attain individually. When organizational members have concrete (and realistically) objectives to pursue, they have something to work towards. In addition, when a strategy is translated into concrete goals, it is easier to be understood by the organizational members, which in its turn is assumed to influence their strategy commitment (Noble, 1999; Kaplan, 1995). Obviously, the lack of concrete objectives and milestones would cause the organizational members do not know what is to be achieved and where the implementation effort is directed to (Noble, 1999; Kaplan, 1995; Cater \& Pucko, 2010; Maas, 2008). Also, concrete execution objectives facilitate execution monitoring, control and evaluation. Without concrete and measurable objectives (and milestones), it could be difficult to monitor whether the execution is on 
track or the adjustments need to be made. Accordingly, concrete implementation objectives allow for rewarding the execution performance of the organizational members. This has a positive influence on their motivation to perform well during the implementation. Cater and Puko (2010) and Maas (2008) observed that when an implementation effort lacks concrete objectives, organizational members cannot be rewarded even when they achieve the objectives; a process that reduces their motivation and performance.

Finally, realistic implementation objectives may give organizational members a challenge, which can have a positive influence on their level of motivation. When the implementation objectives are too ambitious, it can have a very negative influence on the level of motivation of the organizational members. Maas (2008) noted that despite the perceived importance of implementation objectives, it often lacks concrete objectives. He argued that implementation objectives are often too general in nature and too ambitious. Therefore, it is not always clear what the strategy implementation will achieve exactly. It is believed that the lack of concrete objectives contributed to implementation failure at two different organizations. Previous studies conducted by Alamsjah (2011), Cater and Puko (2010), Kaplan (1995), Hambrick and Cannella (1989), Reid (1989), Reed and Buckley (1988) and Wernham (1985) have affirmed the need to always translate the strategy into concrete implementation objectives. They argued that goal setting provides a sense of direction and pace setting for the implementation effort, while inadequate goal specification and misaligned targets can have a negative effect on implementation and organizational performance (Alamsjah, 2011; Cater \& Puko, 2010; Maas, 2008; Kaplan, 1995; Hambrick \& Cannella, 1989; Reid, 1989; Reed \& Buckley, 1988; Wernham, 1985). Thus, there is a strong correlation between execution objective and organizational performance.

\subsubsection{Execution Task and Responsibility}

Scholars (e.g. Maas, 2008; Noble, 1999; Sandy, 1991; Pinto \& Slevin, 1987; Alexander, 1985; Owen, 1982) have pointed out the importance of having a clear implementation tasks and responsibilities. For example, Pinto and Slevin (1987) found that a critical factor for implementation is the detailed specification of the individual steps required for the implementation because when implementation behaviors are not well specified, this may lead to implementation breakdown (Sandy, 1991). This is corroborated by Alexander (1985) who also found that when key implementation tasks and activities are not defined by enough details, this constitutes a barrier to successful implementation. Implementation can only be successful when there is a clear and shared understanding of who does, what, when and what cost (Allio, 2005). Clear responsibility should be allocated for the successful outcome of the implementation. By allocating clear responsibilities for the execution of the implementation activities, progress can be measured and controlled (Reid, 1989). Accordingly, the study by Maas (2008) revealed that when organizational members do not have clear tasks and responsibilities, they may become confused, unmotivated and insecure. Thus, execution task and responsibility will influence the successful outcome of the implementation and consequently affect the overall performance of the organization.

\subsubsection{Execution Tasks}

It is not only about implementation but also how concrete it is. Thus, defining concrete implementation tasks that are needed to achieve the objectives of the implementation are crucial to achieve the organizational goals. Maas (2008) in his study illustrates the following points: first and foremost, organizational members with implementation responsibilities know what specific tasks they have to perform to implement the strategy successfully through implementation tasks. This no doubt assured organizational members certainty about the implementation effort and their role in it, which in turn can have a positive influence on their level of motivation and strategy commitment. Second, organizational members may execute only what they are told to execute and nothing more, but it is required that a very clear implementation task should be assigned to organizational members to assure them that they are executed. Third, there is a need to translate the strategy into concrete implementation tasks and activities. Doing this would force managers to work out the proposed strategy in detail. Finally, defining concrete implementation tasks can make a strategy more concrete to be easily communicated to the organisational members. This is assumed to have a positive influence on implementation performance due to the fact that the organizational members tend to have difficulty in understanding abstract ideas such as a strategy. Strategy execution often lacks a concrete definition of implementation tasks, and due to this organizations tend to have a low level of formalization and an organizational culture, which is oral in nature in the developing countries. Unfortunately, little is documented about implementation tasks and activities. Besides, Maas (2008) observed that defining concrete implementation tasks requires considerable (operational) knowledge of a manager and can take considerable time. 


\subsubsection{Execution Responsibilities}

Assigning clear responsibilities for the performance of implementation tasks is very vital to the general performance of the organization. For example, when clear responsibilities are assigned, organizational members may know what their situation is, and this tends to reduce the uncertainty of organizational members. This is important in strategy implementation because the implementation often creates uncertainty for organizational members.

Furthermore, lack of clear responsibilities makes the organizational members languid and shirks their responsibilities. The evidence by Maas (2008) also attests to this. Further, Maas noted that it is important to be very specific and very detailed in assigning responsibilities to organizational members as a result of group responsibility instead of individual responsibility. By adopting this, no employee will feel individually responsible for a certain task and tends to shift that responsibility to other organizational members. Besides, organizational members have the tendency to do only what they are told and nothing else and are reluctant to take the initiative (Cater \& Puko, 2010; Maas, 2008). However, these tendencies can be taken care off by giving each individual employee a very clear and specific responsibilities and tasks. Finally, when implementation responsibilities are clearly assigned, implementation control may become easier. On the other hand, when implementation objectives are not being achieved as it was planned, the person who is responsible for the achievement of these objectives can be held accountable. However, in the developing countries, for instance, implementations often lack clearly established responsibilities. Their strategies tend to be vaguely formulated and poorly prepared and planned. Apart from that, there is also a lack of a clear description of (implementation) responsibilities due to a low level of formalization (Maas, 2008). This established some sort of association between execution responsibilities and organisational performance.

\subsection{The Strategy Execution Plan (SEP) and Organizational Performance (OP)}

The literature review revealed that there are a few researches on the relationship between strategy execution plan SEP and organizational performance OP. Some studies conducted by Alamsjah (2011); Cuter \& Puko (2010); Maas (2008); Kaplan \& Norton (2005, 2001); Kaplan (1995) focused only on the relationship between SEP and organizational performance OP. According to Alamsjah (2011), Cater \& Puko (2010), Kaplan \& Norton (2005, 2001), Hrebiniak (2005) and Kaplan (1995), the execution plan is vital and crucial for the strategy execution success. Unfortunately, little attention has been extended to execution plan in spite of a considerable number of researches mentioned it as a big obstacle to the success of execution and organizational performance (Mieso, 2010; Rahimian, et, al, 2009; Crittenden \& Crittenden, 2008; Malik, 2007; Delisi, 2006; Alashloo, et.al, 2005; Hrebiniak, 2005; Kaplan \& Norton, 2005; Charan \& Colvin, 2002; Johnson, 2002; Al-Gamdi, 2006, 1998; Alexander, 1991, 1985). Noble (1999), who conducted a study on the execution plan, noted that the execution plan for any organization should have a clear and concrete objective and the tasks of the execution plan should be distributed to the organizational member with understanding the role and responsibility of each member of the strategy execution plan. Accordingly, Hrebiniak and Joyce (1984) and Kaplan \& Norton (2005) affirmed the importance and role of execution plan in the process of successful strategy execution. For example, Kaplan and Norton (2005) believed that without an execution plan, the organization cannot execute its strategy, which implies the failure of the strategy execution, and this would subsequently affect the performance of the organization in general. Thus, it is assumed that there is a strong correlation between strategy execution and organizational performance.

\subsection{Hypothesis Development}

Our literature review revealed any potential findings on the execution plan, strategies and organizational performance. Some of these include Cater and Puko (2010), Mieso (2010), Rahimian, et al (2009), Malik (2007), Delisi (2006, 2001), Hrebiniak (2005), Kaplan and Norton (2005), Charan and Colvin (2002), Johnson (2002), Al-Gamdi $(2006,1998)$ and Alexander (1985). For example, the study by Alamsjah (2011) concurs that strategy execution is the fourth factor out of 11 factors, which can be an obstacle for the success of the organizations and a very critical factor that raises the organizational performance. Similarly, Kaplan (1995) points out that without an execution plan, the organization cannot execute its strategy, and this means that the strategy execution will fail. In the light of the above descriptions coupled with the research framework, the following hypotheses are therefore proposed.

\section{$\mathbf{H}_{\mathbf{1}}$ : A Relationship exists between Strategy Execution Plan, SEP and The Organizational Performance OP.}

$\mathbf{H}_{1 \mathbf{a}}$ : A Relationship exists between Execution Objectives EO and The Organizational Performance. 
$\mathbf{H}_{\mathbf{1 b}}$ : A Relationship exists between Execution Tasks and Responsibilities ETR and The Organizational Performance OP.

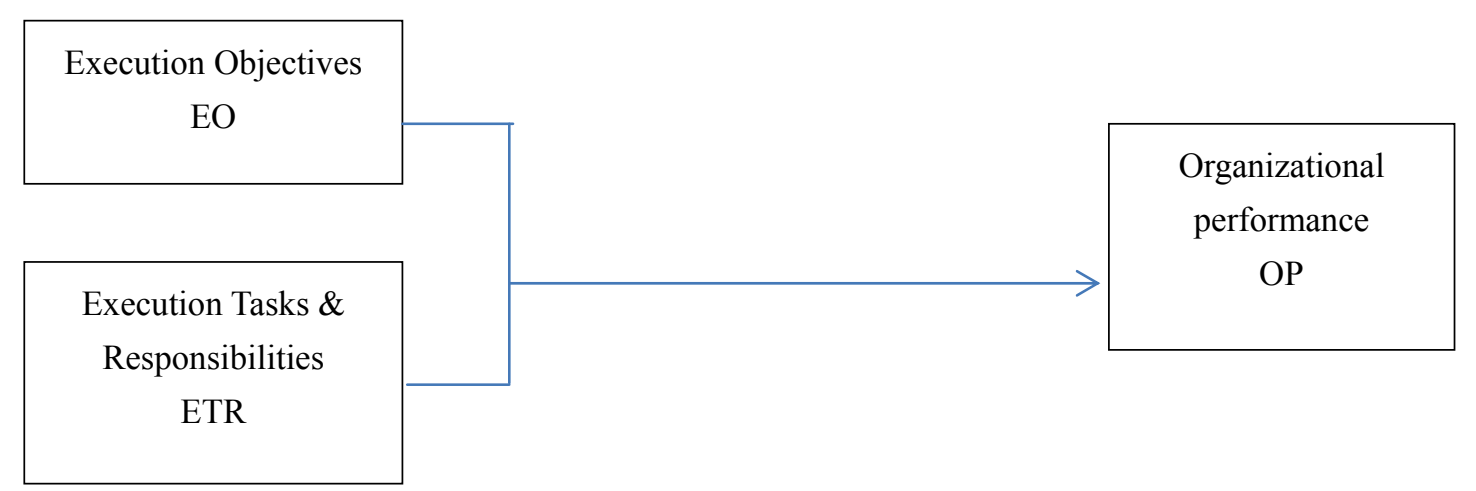

Figure 1. The Research Framework

\section{Methodology}

\subsection{Study Design}

This paper opts for a cross-sectional research design. According to Sekaran (2003), a cross-sectional study is required when there is a need to collect data at a particular point in time. Regarding the sampling technique, a simple random sampling technique was adopted to select 13 universities and colleges from the list of the higher education institution in Palestine. The list of universities and colleges in Palestine was identified through the Palestinian ministry of higher education MOHE through their website. After this, the same sampling technique was also used to select only 255 respondents who finally participated in the study.

\subsection{Measurement of Variables}

To measure the variables, a seven-point Likert scale ranging from $1=$ extremely disagree to $7=$ extremely agree was adopted to measure the extent to which respondents agree or disagree with each of the statements in the questionnaire (Franklin, 2011; Maas, 2008). The independent variable, Execution plan was measured using two dimensions (the execution objective and the execution tasks \& responsibly) of twelfth items reflecting execution plan, while the dependent variable was also measured using the balance score card BSC approach with four perspectives (Kaplan \& Norton, 2006). All the items of organizational performance measures consist of 22 items, adapted and adopted from Franklin's (2011) study.

\section{Data Analysis and Results}

\subsection{PLS Analysis and Result}

Smart PLS was adopted in the analysis of the data due to the many conditions as suggested by Sharma and Kim (2012), Zhang (2009) and Chin (1995). For instance, Sharma and Kim (2012) noted that the use of PLS becomes necessary under conditions of insufficient sample size, while Chin (1995) concurred that PLS is required for data analysis in a situation where there are many indicators and factors involved. Zhang (2009) noted that PLS can deal with both formative and reflective construct, which is the exact situation in this study. Thus, these situations reflect the present study, and therefore the study opted for the use of PLS for the data analysis. Analyses conducted include convergent validity, the discriminant validity, predictive relevance of the model and the bootstrapping, which was used to determine the relationship between the endogenous and exogenous variables.

\subsubsection{The Convergent Validity}

This was used to determine the degree to which the measured constructs correlate positively with a measure of the same construct (Hair, Hult, Ringle and Sarstedt, 2014). It measured the correlation between the formative and reflective constructs. The convergent validity is also determined by examining the loadings, the composite reliability and the average variance extracted. In this case, items, that are of a high load factor 0.7 and with the average variance extracted (AVE) of at least 0.5 and the composite reliability of 0.7 , are all considered acceptable. Table 1 depicts the loadings, reliability (Cronbach's Alpha) and the AVE for this study and indicates that all items met the acceptable limits as suggested by Hair, Hult, Ringle and Sarstedt (2014) and Bagozzi \& Yi (1988). Based on the results in Table 1, the study confirms the adequacy of the level of convergent validity of the measurement model. 
Table 1. Convergent Validity Analysis

\begin{tabular}{|c|c|c|c|c|c|}
\hline Construct & Items & Loadings & $\begin{array}{c}\text { Cronbach's } \\
\text { Alpha }\end{array}$ & $\mathrm{CR}$ & AVE \\
\hline \multirow{6}{*}{$\begin{array}{l}\text { Execution } \\
\text { Objectives }\end{array}$} & ex1 & 0.741 & 0.848 & 0.892 & 0.623 \\
\hline & & & & & \\
\hline & ex2 & 0.826 & & & \\
\hline & ex3 & 0.846 & & & \\
\hline & ex4 & 0.807 & & & \\
\hline & ex5 & 0.720 & & & \\
\hline \multirow{8}{*}{$\begin{array}{c}\text { Execution Tasks \& } \\
\text { Responsibilities }\end{array}$} & $\mathrm{f} 1$ & 0.773 & 0.870 & 0.900 & 0.568 \\
\hline & & & & & \\
\hline & $\mathrm{f} 2$ & 0.825 & & & \\
\hline & $\mathrm{f} 3$ & 0.860 & & & \\
\hline & $\mathrm{f} 4$ & 0.833 & & & \\
\hline & f5 & 0.562 & & & \\
\hline & f6 & 0.697 & & & \\
\hline & $\mathrm{f} 7$ & 0.680 & & & \\
\hline \multirow{6}{*}{$\begin{array}{l}\text { Customer } \\
\text { perspective }\end{array}$} & h1 & 0.806 & 0.872 & 0.904 & 0.613 \\
\hline & h2 & 0.807 & & & \\
\hline & h3 & 0.838 & & & \\
\hline & h4 & 0.839 & & & \\
\hline & h5 & 0.742 & & & \\
\hline & h6 & 0.648 & & & \\
\hline \multirow[t]{6}{*}{ Interior Perspective } & i1 & 0.739 & 0.879 & 0.908 & 0.623 \\
\hline & i2 & 0.764 & & & \\
\hline & i3 & 0.852 & & & \\
\hline & i4 & 0.817 & & & \\
\hline & i5 & 0.812 & & & \\
\hline & i6 & 0.747 & & & \\
\hline \multirow{6}{*}{$\begin{array}{l}\text { Learning \& growth } \\
\text { perspective }\end{array}$} & k1 & 0.759 & 0.825 & 0.873 & 0.534 \\
\hline & $\mathrm{k} 2$ & 0.739 & & & \\
\hline & $\mathrm{k} 3$ & 0.672 & & & \\
\hline & $\mathrm{k} 4$ & 0.806 & & & \\
\hline & $\mathrm{k} 5$ & 0.726 & & & \\
\hline & $\mathrm{k} 6$ & 0.675 & & & \\
\hline \multirow[t]{4}{*}{ Financial perspective } & 11 & 0.858 & 0.761 & 0.849 & 0.590 \\
\hline & 12 & 0.773 & & & \\
\hline & 13 & 0.835 & & & \\
\hline & 14 & 0.571 & & & \\
\hline
\end{tabular}

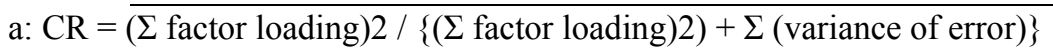

b: AVE $=\Sigma$ (factor loading $) 2 /(\Sigma$ (factor loading $) 2+\Sigma$ (variance of error $)\}$ 


\subsubsection{The Discriminant Validity}

The discriminant validity was used to measure the degree to which agroup of items was able to distinguish the constructs from other constructs in the model as suggested by Fornell and Larcker (1981). By doing this, it was expected that the items of each construct should indicate a variance greater than that shared with other constructs (Compeau et al., 1999). Normally, the discriminant validity is confirmed and assumed if the values of the diagonal elements are higher than other values in their respective rows and columns. Table 2 demonstrates the detailed result of the discriminant validity, including the correlation among variables.

Table 2. Discriminant Validity of Constructs

\begin{tabular}{ccccccc}
\hline $\begin{array}{c}\text { Construct } \\
\text { CP }\end{array}$ & CP & F & IN & LG & PO & PTR \\
\hline F & 0.783 & & & & & \\
IN & 0.469 & 0.768 & & & & \\
LG & 0.540 & 0.489 & 0.545 & 0.731 & & \\
PO & 0.545 & 0.423 & 0.602 & 0.503 & 0.790 & \\
PTR & 0.599 & 0.429 & 0.614 & 0.501 & 0.711 & 0.754 \\
\hline
\end{tabular}

\subsection{The Structural Model, Inner Model and Hypothesis Testing}

This was used to test the proposed hypotheses in order to establish the relationship between the endogenous and exogenous variables. It was done by running the boot strapping in Smart PLS 2.0. Figure 2 and Table 3 below depict the results.

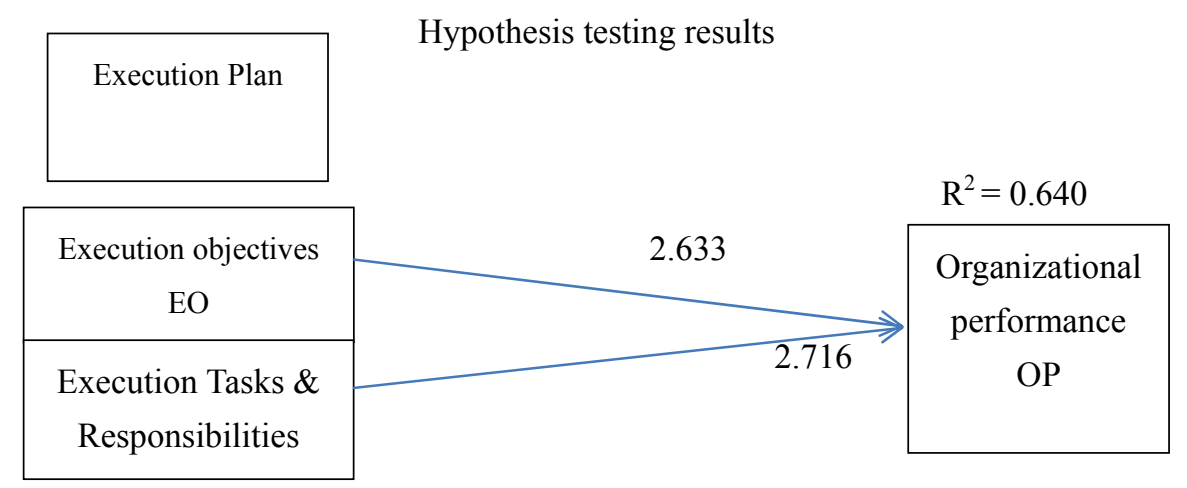

Figure 2. The direct relationship between the independent variables (Strategy execution Plan Dimensions execution objectives and execution tasks and responsibilities) and the dependent variable (organizational performance)

Table 3. Path Coefficients and Hypotheses Testing

\begin{tabular}{ccccccc}
\hline Hypothesis & Hypothesized Path & $\begin{array}{c}\text { Path } \\
\text { Coefficient }\end{array}$ & $\begin{array}{c}\text { Standard } \\
\text { Error }\end{array}$ & T value & P value & Decision \\
\hline $\mathrm{H}_{\mathbf{1}}$ & SEP $->$ OP & $0.363^{* * *}$ & 0.059 & 6.159 & 0.000 & Supported \\
$\mathrm{H}_{1 \mathbf{a}}$ & EO -> OP & $0.170^{* *}$ & 0.064 & 2.633 & 0.004 & Supported \\
$\mathrm{H}_{\mathbf{1 b}}$ & ETR $->$ OP & $0.156^{* *}$ & 0.057 & 2.716 & 0.003 & Supported \\
\hline
\end{tabular}

From Figure 2 and Table 3, it is revealed that the SEP has a positive and significant effect on the OP at the 0.001 level of significance $(\beta=0.363, \mathrm{t}=6.159, \mathrm{p}<0.001)$. The result further revealed that PO has a positive and significant effect on the organizational performance at the 0.05 level of significance $(\beta=0.170, t=2.633, p<0.05)$. 
Similarly, the PTR also has a significant and positive effect on the organizational performance at the 0.05 level of significance $(\beta=0.156, \mathrm{t}=2.716, \mathrm{p}<0.05)$. Thus, the hypotheses $\left(\mathrm{H}_{1}, \mathrm{H}_{1 \mathrm{a}}\right.$, and $\left.\mathrm{H}_{1 b}\right)$ for this study are well supported.

\subsection{Predictive Relevance of the Model}

$\mathrm{R}^{2}$ and Cross-validated redundancy was utilized to examine the predictive power of the model. $\mathrm{R}^{2}$ refers to the variance in the endogenous variables that are explained by the exogenous variables. Table 4 revealed the $R_{2}$ represents $40.3 \%$ of the Organizational Performance that was explained by the execution objectives. Accordingly, $40.3 \%$ of the Organizational Performance was accounted for by the execution tasks and responsibilities. In line with the findings of this study, Cohen (1988) suggested a value of $\mathrm{R}^{2}$, where 0.26 is substantial, 0.13 is moderate, and 0.02 is weak. Therefore, both $R^{2}$ values for this study are considered substantial and the power of variables is contained in the model in explaining the organizational performance.

Furthermore, the study also used the $\mathrm{R}^{2}$, the Cross-Validated Redundancy values to assess the quality of the model. This was done by conducting the Blindfolding procedures. These values in Smart PLS were applied with a view to generate the cross-validated redundancy and cross-validated communality. To do this, the study removed sum of the values in the data which was later estimated as a missing value. After that, the estimated parameters were used to re- estimate the missing data and a comparison of the output were conducted. Table 4 provides the detailed results on the output as the cross-validated redundancy.

Table 4. Prediction Relevance of the Model

\begin{tabular}{cccc}
\hline Construct & R square & $\begin{array}{c}\text { Cross Validated } \\
\text { Redundancy }\end{array}$ & $\begin{array}{c}\text { Cross Validated } \\
\text { Communality }\end{array}$ \\
\hline Organizational Performance & 0.403 & 0.256 & 0.640 \\
Execution Objectives & & & 0.817 \\
Execution Tasks \& Responsibilities & & & 0.890 \\
\hline
\end{tabular}

According to Fornell and Cha (1994), the model under investigation will have the predictive quality if the cross-redundancy values were more than zero, else the predictive quality of the model cannot be confirmed. Table 4 showed the obtained cross validated redundancy of 0.25 for OP. Therefore, these results confirmed that the model has adequate prediction quality.

\subsection{Goodness of Fit (GoF) of the Model}

PLS-SEM has only one measure of goodness of fit that was defined by Tenenhaus et al. (2005) to be the global fit. Therefore, it is the geometric mean of the AVE and the average $\mathrm{R}^{2}$ for the endogenous variable in the following formula:

$$
\text { Gof }=\sqrt{\left(R^{2} \times \overline{A V F)}\right.}
$$

The baseline values of GoF suggested by Wetzels et al. (2009) is ( small $=0$. 1, medium $=0.25$, large $=0.36$ ). Accordingly, in this study, the GoF value was 0.658 which is regarded to be large. Therefore, the results showed that the model GoF measure is large based on the average variance, which refers to an adequate level of PLS model validity.

Table 5. Goodness of Fit GoF

\begin{tabular}{cccc}
\hline Construct & R square & AVE & GoF \\
\hline Execution Objectives & 0.817 & 0.623 & \\
Execution Tasks \& Responsibilities & 0.890 & 0.568 & \\
Customer Perspective & 0.774 & 0.613 & \\
Internal Perspective & 0.801 & 0.623 & \\
Learning \& Growth Perspective & 0.595 & 0.534 & \\
Financial Perspective & 0.476 & 0.590 & 0.658 \\
Average & 0.725 & 0.591 &
\end{tabular}




\section{Discussions and Implications}

The major aim of this paper was to examine the influence of the strategy execution plan on the organisational performance in the Palestinian Higher Education. Specifically, the study examined the influence of strategic execution plan dimensions, namely execution objective and the execution tasks and responsibilities on the organisational performance. First, the study found the overall influence of the strategy execution plan on the organisational performance. In other words, the study found that strategy execution plan is significantly related to the organisational performance. The results suggest that the higher education in Palestine can be enhanced through an effective strategy execution. The result revealed a positive and significant effect of the execution plan on organizational performance ( 0.001 levels of significance; $\beta=0.363, t=6.159, p<0.001)$. This finding is consistent with previous findings by Alamsjah (2011), Cater and Pucko (2010), and Grittenden and Grittenden (2008), who indicated that strategy execution plan impacts organisational performance.

Furthermore, the results revealed that the two dimensions of the strategy execution plan, namely execution objectives and execution tasks and performance are positively and significantly related to the organisational performance. Specifically, the results found that the execution objectives have a positive and a significant effect on organizational performance ( 0.05 levels of significance; $\beta=0.170, t=2.633, p<0.05)$. Accordingly, further results on the dimension indicates that the execution tasks and performance positively and significantly influence organizational performance ( 0.05 levels of significance; $\beta=0.156, t=2.716, p<0.05)$. Our findings support the previous studies by Rahmonian, et al. (2009), Maas (2008), Alashloo, et al (2005) and Noble (1999). They found that higher institutions, such as the universities, can effectively execute their plans (Rahmonian, et al., 2009; Maas, 2008; Alashloo, et al. 2005; Noble, 1999a, b). Our findings suggest that execution plan and its dimensions considered in this study are positively and significantly related to the organisational performance.

Our study contributes in many different aspects. First, the study extends the literature in this area by examining the relationships between execution plan and its dimensions (execution objectives, execution tasks and responsibilities) and organizational performance with a particular interest in higher education in Palestine which may be considered unique due to the current situation in Palestine. Apart from this, our study seems to be an initial study to examine the influence of the execution plan and its dimensions as no literature has indicated this. Academically, we believe that the present study would open a door for other researchers to investigate more and examine other factors that play a role in this relationship.

Furthermore, the study findings obtained in this study would be a huge benefit to the higher educations across the globe including Palestine. It is believed that our findings would help the administrators of higher education, including the policy makers to take proper and good decisions regarding program execution and implementations. For the practitioners, managers inclusive, the SEP factors would strongly raise their awareness on the need to effectively execute and implement organisational programs and projects with a view to achieve the organisational performance.

\section{References}

Alamsjah, F. (2011) Key Success Factors in Implementing Strategy: Middle-Level Managers' Perspectives. Procedia Social and Behavioral Sciences, 24, 1444-1450

Alashloo, F. R., Castka, P., \& Sharp, J. M. (2005). Toward Understanding the Impeders of Strategy Implementation in Higher Education (HE) A Case of HE institutes in Iran. Quality Assurance in Education, 13(2), 132-147.

Alexander, L. D. (1985). Successfully implementing strategic decisions. Long Range Planning, 18(3), 91-7.

Alexander, L. D. (1991). Strategy Implementation: Nature of the problem. In D. E. Hussey (Ed.), International Review of Strategic Management, 2(1).

Al-Gamdi, S. M. (1998). Obstacles to Successful Implementation of Strategic Decisions, The British Experience. European Business Review, 6, 322-327.

Al-Gamdi, S. M. (2006). Obstacles to Successful Implementation of Strategic Decision: The Saudi Case. King Fahed University of Petroleum \& Minerals for the Development, the SABIC grant.

Allio, M. K. (2005). A short, practical guide to implementing strategy. The Journal of Business Strategy, 26(4), $12-21$.

Bagozzi, R. P., Youjae, Y., \& Phillips, L. W. (1991). Assessing Construct Validity in Organizational Research. Administrative Science Quarterly, 36, 421-458. http://dx.doi.org/10.2307/2393203

Bossidy L, Charan, R., \& Burck, C. (2002). Execution: The discipline of getting things done. Crown Business: 
New York.

Brinkerhoff, D. W. (1996). Process Perspectives on Policy Change: Highlighting Implementation. World Development, 24(9), 1395-1401.

Cater, T., \& Pucko, D. (2010). Factors of Effective Strategy Implementation: Empirical Evidence from Slovenian Business Practice. Journal for East European Management Studies JEEMS, 207-237.

Charan, R., \& Colvin, G. (2002). Why CEOs Fail. Fortune Archives.

Chin, W. W. (1995). In G. A. Marcoulides (Ed.), The Partial Least Squares Approach to Structural Equation Modelling: Modern Methods for Business Research (pp. 295-336). Laurence Erlbaum Associates, Mahwah, New Jersey.

Chin, W. W. (1998) .The partial least squares approach to structural equation modeling. In G. A. Marcoulides (Ed.), Modern methods for business research (pp. 295-336). Mahwah: Lawrence Erlbaum.

Cohen, J. (1988). Statistical Power Analysis for the Behavioral Science. Hillsdale, Erlbaum.

Crittenden, V. L., \& Crittenden, W. F. (2008). Building Capable Organization: The Eight Levers of Strategy Implementation. Business Horizons, 51, 301- 309.

Delisi, P. S. (2006). Strategy Execution: An Oxymoron or a Powerful Formula for Corporate Success? Organizational Synergies.

Fornell C., \& Larcker, D. F. (1981). Evaluating structural equation models with unobservable variables and measurement error. Journal of Market Research, 18(1), 39-50.

Fornell, C., \& Cha, J. (1994). Partial least squares. In R. P. Bagozzi (Ed.), Advanced methods of marketing research (pp. 52-78). Cambridge: Blackwell.

Franklin, P. W. (2011). Relationship between Strategic Planning and Nonprofit Organizational Performance. ProQuest LLC, USA.

Galbraith, C. S., Merrill, G. B. (1991). The effect of compensation program and structure on SBU competitive strategy: A study of technology-intensive firms. Strategic Management Journal, 12(5), 353-370.

Gurkov, I. (2009). Strategy process as formulation and realization of corporate goals: The synthesis of surveys in Russian firms. Journal for East European Management Studies, 14(1), 48-64.

Hair, J. F. Jr., Black, W. C., \& Babin, B. J. (2012). Multivariate data analysis (7th ed.). Upper Saddle River, NJ: Prentice Hall.

Hair, J. F., Ringle, C. M., \& Sarstedt, M. (2011). PLS-SEM: Indeed a Silver Bullet. Journal of Marketing Theory and Practice, 19(2), 139-151. http://dx.doi.org/10.2753/MTP1069-6679190202

Hambrick, D. C., \& Cannella, A. A. (1989). Strategy Implementation as Substance and Selling. Academy of Management Executive, 3(4), 278-285.

Higgins, J. M. (2005). The Eight 'S's of successful Strategy Execution. Journal of Change Management, 5(1), 3-13.

Hoskisson, R. E., Hitt, M. A., \& Hill, C. W. L. (1993). Managerial incentives and investment in R\&D in large multi-product firms. Organization Science, 4, 325-341.

Hrebiniak, L. (2008). Making Strategy Work: Overcoming the Obstacles to Effective Execution. IVEY Business Journal.

Hrebiniak, L. G. (2006). Obstacles to Strategy Implementation. Organizational Dynamics, 35(1), 12-31.

Hrebiniak, L. G., \& Joyce, W. F. (1984). Implementing Strategy. Newyork. McMillan.

Hussy, D. (2002). Company Analysis: Determining Strategic Capability. Strategic Change, 11, 43-52.

Hussy, D. E. (1996). The Implementation Challenge. Chichester: John Wiley, London.

Johnson, G., \& Scholes, K. (2001). Exploring Corporate Strategy, Englewood Cliffs. NJ: Prentice Hall.

Johnson, P. (2002). The Top Five Reasons Why Strategic Plans Fail. Retrieved from http://www.businessknowhow.com/manage/splanfail.htm

Kaplan, R. (1995). Building a Management System to Implement Your Strategy: Strategic Management Survey: Summary of Findings and Conclusions. London: Renaissance Solutions. 
Kaplan, R. S., \& Norton, D. P. (1996). Using the Balance Scorecard as a Strategic Management System. Harvard Business School Review, 74(1), 75-85.

Lynch, R. (2003). Corporate Strategy (3rd ed.). Edinburgh Gate, Harlow: Pearson Education Limited.

Maas, V. D., \& Arnoud, A. (2008). Strategy Implementation in a Small Island Community. An Integrative Framework (PhD Thesis). Erasmus University Rotterdam.

Mintzberg, H. (1990). The Design School: Reconsidering the Basic Premises of Strategic Management. Strategic Management Journal, 11(3), 171-195.

Neilson, G. I., Martin, K. L., \& Powers, E. (2007). The Secrets to Successful Strategy Execution. Harvard Business Review.

Noble, C. H. (1999). The Eclectic Roots of Strategy Implementation Research. Journal of Business Research, 45, 119-134.

Noble, C. H., (1999). Building the Strategy Implementation network. Business Horizons, 42(6), 19-28.

Okumas, F. (2002). Can Hospitality researches Contribute to the Strategic Management Literature?. Hospitality Management, 21, 105-110.

Okumas, F. (2003). Towards a Strategy Implementation Framework. Hospitality Management, 13(7), 327-338.

Okumus, F. (2001). Towards a strategy implementation framework. International Journal of Contemporary Hospitality Management, 13(7), 327-338.

Rahimnia, F., Polychronakis, Y., \& Sharp, J. M. (2009). A Conceptual Framework of Impeders to Strategy Implementation from an Exploratory Case Study in an Iranian University. Education, Business and Society: Contemporary Middle Eastern Issues, 246- 261.

Reed, R., \& Buckley, M. R. (1988). Strategy in Action - Techniques for Implementing Strategy. Long Range Planning, 21(3), 67-74.

Reid, D. M. (1989). Operationalizing Strategic Planning. Strategic Management Journal, 10(6), 553-567.

Sharma, P. N., \& Kim, K. H. (2012). A Comparison of PLS and ML Bootstrapping techniques in SEM: A Monte Carlo Study.

Tenenhaus, M., Esposito Vinzi, V., Chatelin, Y. -M., \& Lauro, C. (2005). PLS path modeling. Computational Statistics \& Data Analysis, 48(1), 159-205.

Wernham, R. (1985). Obstacles to Strategy Implementation in a Nationalized Industry. Journal of Management Studies, 22(6), 632-647.

Wetzels, M., Odekerken-Schröder, G., \& Oppen, C. V. (2009). Using PLS path modeling for assessing hierarchical models: Guidelines and empirical illustration. MIS Quarterly, 33(1), 177-195.

Zhang, Y. (2009). A Study of Corporate Reputation's Influence on Customer Loyalty Based on PLS-SEM Model. International Business Research, 2(3), 28-35. http://dx.doi.org/10.4018/jebr.2006070103

\section{Copyrights}

Copyright for this article is retained by the author(s), with first publication rights granted to the journal.

This is an open-access article distributed under the terms and conditions of the Creative Commons Attribution license (http://creativecommons.org/licenses/by/3.0/). 